\title{
TRIATRIAL HEART
}

\author{
BY \\ CHRISTOPHER S. DARKE, JOHN L. EMERY, AND JOHN LORBER \\ From the Department of Child Health and the University, the Children's Hospital, and \\ the City General Hospital, Sheffield
}

Triatrial heart is a rare form of congenital heart disease and may be associated with other developmental anomalies. In this condition, a diaphragm divides the left atrium into two cavities that communicate through a small opening. This results in a fairly characteristic clinical picture. Since the barrier imposes an intolerable burden on the heart and lesser circulation its recognition during life is a matter of importance and some urgency, since surgical removal of the diaphragm is not a difficult procedure. The purpose of this paper is to record another case of this anomaly and to emphasize the difficulties in reaching the diagnosis, even with the aid of full cardiac investigations, including cardiotomy.

\section{Case Report}

The patient, a girl, was born at home and weighed $6 \mathrm{lb} .12 \mathrm{oz} .(3000 \mathrm{~g}$.). Her mother, who was 30 years of age, had had pneumonia in the sixth month of pregnancy, and for many years had had chronic bronchitis. The father, aged 51, had mitral stenosis. There had been two siblings, of whom one died at the age of 10 days and the other was healthy. There had been no miscarriages.

She had no illnesses until two years of age when she was admitted to hospital with pneumonia. From that time onwards she had a persistent cough. During the next 30 months she had six further attacks of pneumonia or bronchiolitis which were treated in hospital. All this time a loud systolic murmur was heard in the mitral area. On one occasion a mitral diastolic murmur also was heard.

Investigations showed that she was tuberculin negative (100 T.U. of O.T., Mantoux). Trypsin was present in the stools and duodenal juice. The plasma proteins were normal. The chest radiographs always showed prominent hilar vascular shadows and some irregular densities in the lung fields particularly affecting the right middle lobe (Fig. 1). No hilar dance was seen on screening of the chest. On two occasions bronchograms showed no abnormalities. Bronchoscopy showed no localized disease of the main bronchi.

In view of prominent and persistent rales and the nodular shadows shown on the radiographs, it was thought possible that she had an interstitial pulmonary fibrosis resulting from previous attacks of pneumonia. Pulmonary hæmosiderosis was also considered, but gastric washings on a number of occasions failed to reveal the presence of hæmosiderin granules. At the age of $6 \frac{1}{2}$ years an inconstant diastolic murmur at the apex was again heard, as well as the more obvious blowing systolic murmur, which had been present throughout. In addition there was a loud split pulmonary second sound, palpable closure of the pulmonary valves, and a systolic lift over the right ventricular outflow tract, indicating pulmonary hypertension. Because of the mitral murmurs and the possible pulmonary hæmosiderosis, it was thought that she had mitral stenosis of congenital origin. An electrocardiogram showed sinus rhythm and a right bundle-branch block pattern in V1.

At the age of 7 years, cardiac catheterization was performed by Dr. T. L. Morris. A mean pressure of between 40 and $60 \mathrm{~mm}$. $\mathrm{Hg}$ was recorded in the right, and one of $60 \mathrm{~mm}$. in the left, pulmonary artery. Wedge pressure from the peripheral part of each lung was $40 \mathrm{~mm}$. The mean right ventricular pressure was $30 \mathrm{~mm}$. Tracings taken from the wedged position in the right lung showed giant $a$ waves. Angiocardiography was not helpful because the left side of the heart was not adequately filled by the contrast medium. It was concluded that she had mitral stenosis with pulmonary hypertension.

Four months later, a cardiotomy was performed. Very dilated and tense pulmonary veins were seen and some difficulty was found in entering what appeared to be a very small left atrium. Exploration of this chamber did not reveal any tumour or antemortem thrombus and the mitral valve felt normal. A finger passed easily into the left ventricle and there appeared to be slight regurgitation. No atrial or ventricular septal defect was detected. The most striking abnormality was the minute size of the left 
atrium which was about the size of a large walnut. The lungs were indurated and a biopsy of the lingular segment of the left upper lobe showed evidence of pulmonary hypertension and areas of focal hæmosiderosis.

The post-operative course was complicated by acute pulmonary œdema. Digoxin and mersalyl caused a good diuresis and she was discharged home about two months later. For almost two years there was less dyspnoa, but there was a prominent diastolic murmur, having the classical features of mitral stenosis. At the age of nine, she was admitted extremely ill with high fever, cyanosis, and breathlessness, and then had signs of lobar pneumonia and of congestive cardiac failure. She had also some degree of sexual precocity, the breasts and pubic hair being well developed. She developed atrial fibrillation, which was not controlled by digoxin, and she died five days later.

Necropsy. All the important lesions were in the thoracic cavity. The rest of the body showed venous congestion, but no gross œdema. There were bilateral pleural effusions. The lungs were unusually firm, heavy, and mottled, but no evidence of consolidation was seen.

There was a fine fibrinous pericarditis. The heart was grossly enlarged. The systemic venous return was normal. The right atrium appeared enlarged and the foramen ovale was completely obliterated. The tricuspid valve appeared normal. The right ventricle was large and the wall was thick $(8-12 \mathrm{~mm}$.). A normal pulmonary valve opened into a large and unusually thick-walled pulmonary artery.

The pulmonary veins appeared normal. They entered the atrium at their normal situation, but the left atrium was seen to consist of two separate cavities (Fig. 2). These communicated through an opening, approximately $6 \mathrm{~mm}$. in maximum diameter. The dividing membrane ran obliquely across the atrial appendage at a level of $1 \mathrm{~cm}$. above the mitral valve. The mitral valve was not attached to the abnormal septum. The mitral valve, aorta, and vessels showed no gross abnormalities. The wall of the left ventricle was $10 \mathrm{~mm}$. thick.

Histology. The lungs showed a general increase in connective tissue, and numerous alveoli contained large macrophages, some of which had old blood pigment. The major feature of the lungs, however, was disease of the arteries. There was a diffuse obliterating arteritis with active proliferation of the intima. In addition there were many almost completely obliterated small arteries. These changes were patchy and some of the small muscular arteries appeared to be completely normal. The large pulmonary arteries showed changes similar to those seen in the main pulmonary trunk.

The membrane across the left atrium had a central fibrous core in which were masses of what appeared to be normal atrial muscle, and both sides of the membrane had a fibro-elastic structure similar to that of the 

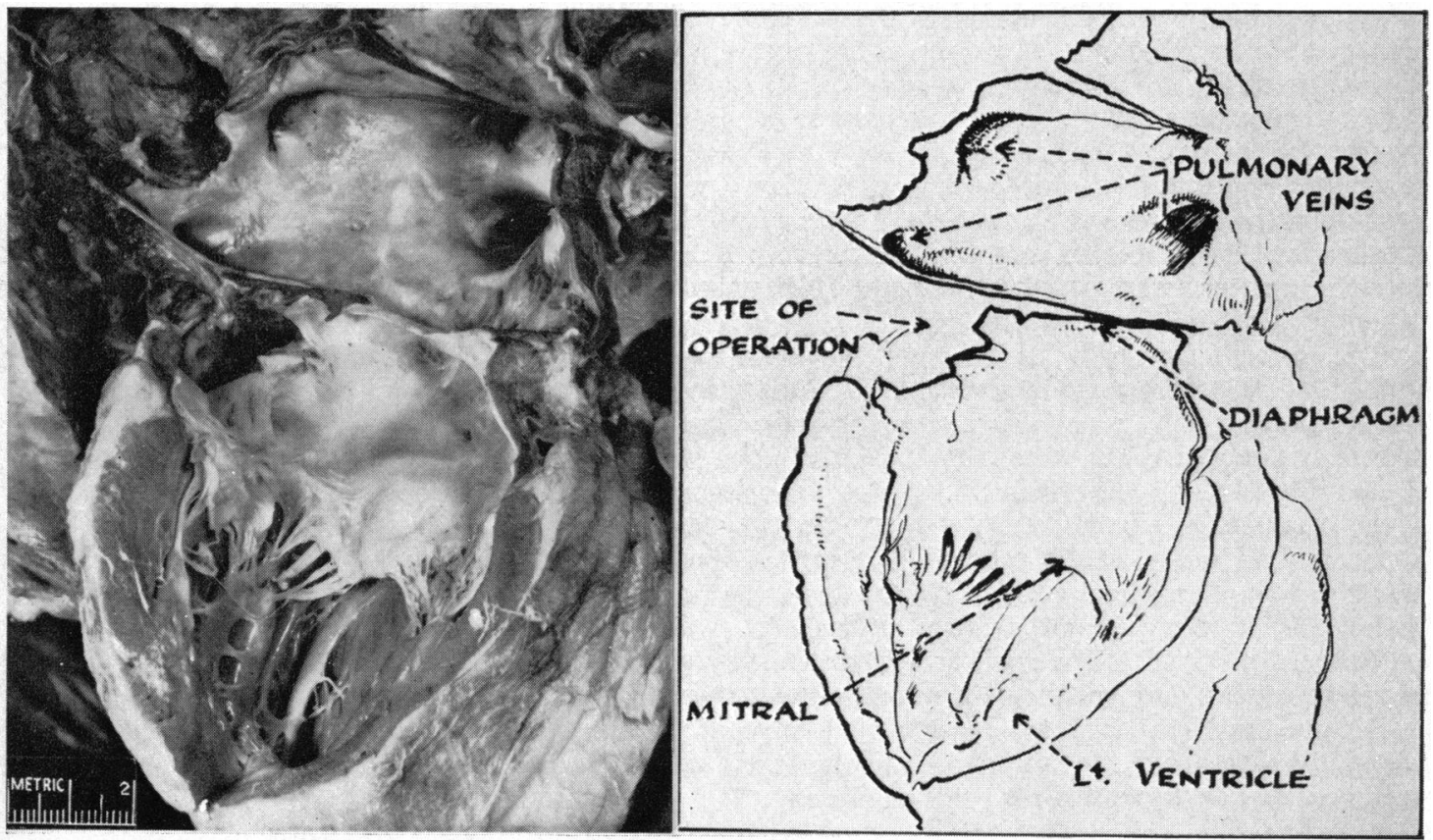

Fig. 2.-The appearance of the heart at necropsy, showing the normal mitral valve and the position of the septum between the two chambers of the left atrium. The pulmonary venous drainage is normal.

arterial wall. There was an abnormal muscularization of the root of the mitral valve in the area where the abnormal septum impinged. Elsewhere the rest of the heart was normal, except for some possible irregularity in the thickness of the ventricular endocardium, and some possible increase in connective tissue septa in the right ventricle.

The aorta appeared to be histologically normal $(0.9 \mathrm{~mm}$. thick). The pulmonary artery was very thick $(1.5 \mathrm{~mm}$.). This thickening appeared to be largely due to an increase in the amount of connective and muscular tissue between the elastica bundles, these bundles being unusually fragmented and widely separated.

\section{Discussion}

Triatrial heart is a rare malformation. The condition has been thoroughly reviewed by Keith $e t$ al. in 1958. Some 29 cases have so far been published including an earlier case from this Department (Doxiadis and Emery, 1953). The ætiology of the condition has not been fully determined, though the majority of recent workers favour Griffith's early view (1902) that it results from a failure of incorporation of the embryonic common pulmonary vein into the left atrium. The reported cases are very similar to that described in our patient. A septum divides the left atrium into two chambers, the postero-superior chamber being relatively medial and receiving the pulmonary veins. Inferiorly it communicates through a narrow ostium with the second chamber of the left atrium. The mitral valve is normal. The septum dividing the left atrium produces a mechanical and a clinical picture that simulates the picture of a tight mitral stenosis. The time of onset of the symptoms depends on the size of the ostium between the two chambers. As it is often very small, symptoms usually appear in infancy. In our patient the ostium was moderately large, and this explains the relatively late onset of her symptoms, and her survival for 9 years. Occasionally the ostium is large, when symptoms may be slight and prolonged survival is possible (Loeffler, 1949). Nevertheless, even with a very small ostium of $2 \mathrm{~mm}$. in diameter, Belcher and Somerville's (1959) patient reached 28 years of age before an operation was undertaken to relieve the obstruction.

On physical examination of the heart an apical diastolic murmur was only rarely heard in the published cases, though it was present intermittently in our patient. A pan-systolic murmur was much more common. The electrocardiogram usually showed a right atrial and right ventricular hypertrophy. 
Radiologically the heart may be of normal size or show enlargement of the right ventricle. The pulmonary conus is prominent, as are the major vessels at the lung roots. There is no hilar dance. There is congestion of the peripheral pulmonary vessels, sometimes associated with edema of the lungs of the butterfly wing distribution. This was present in the patients of Keith et al. (1958). Our patient also showed this feature, as well as nodular shadows in the lung fields suggestive of hæmosiderosis, which was confirmed at necropsy. Angiocardiographic investigations have not been reported in the past, and did not help in the diagnosis of our patient. Cardiac catheterization has rarely been performed (Pederson and Therkelsen, 1954; Vineberg and Gialloreto, 1956; Barrett and Hickie, 1957): high right ventricular and pulmonary artery pressures and particularly a high pulmonary artery wedge pressure have been found. Our patient also showed these features.

The correct diagnosis in life has not so far been made except at cardiotomy in four adult patients (Lewis et al., 1956; Vineberg and Gialloreto, 1956; Barrett and Hickie, 1957; and Belcher and Somerville, 1959). The symptoms and signs and the results of investigations are highly suggestive of mitral stenosis, but usually present at a very early age when mitral stenosis is very rare. Triatrial heart, therefore, should be considered in the differential diagnosis in such patients. The absence of an enlargement of the left atrium is in favour of the diagnosis of triatrial heart. The differential diagnosis can be finally resolved at cardiotomy. Unfortunately, in our patient the possibility that she might have triatrial heart was not considered and its presence was not recognized, so that the opportunity to relieve the obstruction was lost. Barrett and Hickie (1957) had a similar experience at their first cardiotomy: the condition might have been thought of, as the pulmonary veins remained grossly distended even after opening the atrium and finding a normal mitral valve; but they performed a second cardiotomy and dealt with the lesion.

Treatment of triatrial heart consists of division of the abnormal septum. This has been successfully accomplished so far in the four adult patients mentioned, but we have found no record of any child having been operated on successfully for this condition.

\section{Summary}

We report a nine-year-old child who from the age of two years onwards repeatedly suffered from pulmonary congestion and later heart failure. The clinical picture and investigations suggested that she had mitral stenosis, but at operation the mitral valve was normal. Distension of the pulmonary veins suggested an obstruction, but its situation was not located, and the obstruction was not relieved. The child died two years later, and at necropsy her left atrium was found to be divided by a septum, through which an opening of $6 \mathrm{~mm}$. in diameter was present. This is the classical appearance of triatrial heart.

We are grateful to Mr. A. W. Fawcett who operated on our patient for details of his operative findings, and to Professor Illingworth for his critical comments.

\section{References}

Barrett, N. R., and Hickie, J. B. (1957). Thorax, 12, 24.

Belcher, J. B., and Somerville, W. (1959). Brit. med. J., 1, 1280.

Doxiadis, S. A., and Emery, J. L. (1953). J. Pediat., 42, 87.

Griffith, T. W. (1902). J. Anat. Physiol., 37, 255.

Keith, J. D., Rowe, R. D., and Vlad, P. (1958). Heart Disease in Infancy and Childhood, p. 352. Macmillan, New York.

Lewis, F. J., Varco, R. L., Taufic, M., and Niazi, S. A. (1956). Surg. Gynec. Obstet., $102,713$.

Loeffler, E. (1949). Arch. Path., 48, 371

Pedersen, A., and Therkelsen, F. (1954). Amer. Heart J., 47, 676.

Vineberg, A., and Gialloreto, O. (1956). C Canad. med. Ass. J., 74, 719. 